\title{
Alcohol acute intoxication before sepsis impairs the wound healing of intestinal anastomosis: rat model of the abdominal trauma patient
}

Pedro Henrique Alves de Morais', Vinícius Lacerda Ribeiro', Igor Eduardo Caetano de Farias', Luiz Eduardo Almeida Silva ${ }^{1}$, Fabiana Pirani Carneiro ${ }^{2}$, Joel Paulo Russomano Veiga ${ }^{2}$, João Batista de Sousa ${ }^{1,3^{*}}$

From World Trauma Congress 2012

Rio de Janeiro, Brazil. 22-25 August 2012

\begin{abstract}
Introduction: Most trauma patients are drunk at the time of injury. Up to $2 \%$ of traumatized patients develop sepsis, which considerably increases their mortality. Inadequate wound healing of the colonic repair can lead to postoperative complications such as leakage and sepsis.

Objective: To assess the effects of acute alcohol intoxication on colonic anastomosis wound healing in septic rats.

Methods: Thirty six Wistar rats were allocated into two groups: S (induction of sepsis) and AS (alcohol intake before sepsis induction). A colonic anastomosis was performed in all groups. After 1, 3 or 7 days the animals were killed. Weight variations, mortality rate, histopathology and tensile breaking strength of the colonic anastomosis were evaluated.

Results: There was an overall mortality of 4 animals (11.1\%), three in the group AS (16.6\%) and one in the S group (5.5\%). Weight loss occurred in all groups. The colon anastomosis of the AS group didn't gain strength from the first to the seventh postoperative day. On the histopathological analysis there were no differences in the deposition of collagen or fibroblasts between the groups AS and S.

Conclusion: Alcohol intake increased the mortality rate three times in septic animals. Acute alcohol intoxication delays the acquisition of tensile strength of colonic anastomosis in septic rats. Therefore, acute alcohol intoxication before sepsis leads to worse prognosis in animal models of the abdominal trauma patients.
\end{abstract}

\section{Introduction}

Abdominal trauma patients are often acutely intoxicated with alcohol, and one of the injuries they can suffer is the rupture of the colon. This injury leads to leakage of feces into the abdominal cavity, and has as consequences peritonitis and sepsis. After surgery, the prognosis of the patient depends to a large extent on the wound healing of the colon.

Healing is a sequential and organized biological process which aims to repair damaged tissue and reunite

\footnotetext{
*Correspondence: sousajb@unb.br

'Medical School, Academic League of Emergency and Trauma, University of Brasilia, Brasilia, Brazil

Full list of author information is available at the end of the article
}

the edges of the wound, to finally restore both the organ's physiological functions and the barrier that separates the external and internal environments [1]. It can be divided into four sequential steps: hemostasis, inflammation, proliferation and remodeling [1].

Inadequate wound healing is responsible for postoperative colonic repair complications such as dehiscence and leakage. The postoperative rate of anastomotic leakage in abdominal trauma patients varies from $7 \%$ to $14 \%$ in low risk patients, and can be as high as $40 \%$ in higher risk patients [2]. These complications are responsible for longer hospital stay, reoperation and increased morbidity and mortality $[2,3]$.

\section{() Biomed Central}

(C) 2012 Morais et al; licensee BioMed Central Ltd. This is an Open Access article distributed under the terms of the Creative Commons Attribution License (http://creativecommons.org/licenses/by/2.0), which permits unrestricted use, distribution, and reproduction in any medium, provided the original work is properly cited. 
Studies have shown that up to $2 \%$ of traumatized patients develop sepsis, which considerably increases the mortality if compared to non-septic individuals [4].

Sepsis was the 11th leading cause of death in the U.S. in 2003 and in Brazil the prevalence and mortality are high, with up to $60 \%$ of mortality in septic chock [5].

Alcohol is the most consumed drug in the world [6]. Epidemiological data of the emergency units and intervention studies indicate that most patients seen by some traumatic disorder were drunk [7-9].

Over $50 \%$ of the beds for trauma are occupied by patients who were acutely intoxicated by alcohol at the time of injury [10]. The intake of alcohol contributes to worsen the injuries caused by trauma and can complicate the management of these patients.

The aim of this study was to assess the impact of acute alcohol intoxication on colonic anastomosis wound healing in rats under sepsis in an experimental model of the abdominal trauma patient.

\section{Materials and methods}

This randomized blinded experimental study was performed after the consent of the Ethics Committee of Animal Usage (CEUA), University of Brasilia. All procedures were guided by ethical standards proposed by the Brazilian College of Animal Experimentation (COBEA).

The study was designed with 36 male Wistar rats, which were randomly allocated into two groups of 18 animals each:

$\checkmark$ GROUP S (Sepsis): anesthesia, sepsis induction, segmental colectomy, colonic anastomosis, wound healing evaluation.

$\checkmark$ GROUP AS (Alcohol and Sepsis): alcohol intake, anesthesia, sepsis induction, segmental colectomy, colonic anastomosis, wound healing evaluation.

Each group was subdivided into three subgroups of six animals, to be euthanized after 1,3 or 7 days postoperatively (POD), named as:

$\diamond$ GROUP S: S1, S3 and S7;

$\checkmark$ GROUP AS: AS1, AS3 and AS7;

On the operation day the rats were fasted for one hour. The animals of the AS group were alcoholized with ethanol diluted in saline to a concentration of $40 \%$ with a standard dose of $2 \mathrm{ml}$ of solution. This dose is equivalent to a $480 \mathrm{~mL}$ spirits intake or approximately 10 shots, in a young adult male of $75 \mathrm{~kg}$ of weight. Half of the dose $(1 \mathrm{ml})$ was administered by mouth, using the gavage method. Another $1 \mathrm{ml}$ was given one hour later also by mouth, immediately before anesthesia. The surgeons were blinded to whether the rats had received alcohol or not.

The anesthetic induction was performed with xylazine in a dose of $10 \mathrm{mg} / \mathrm{kg}$, and ketamine at a dose of $75 \mathrm{mg} / \mathrm{kg}$, both intramuscularly. Then the abdomen was cleaned with iodinated detergent.
A midline abdominal incision that began one centimeter cranial to the pubis symphysis, with a length of approximately $4.5 \mathrm{~cm}$, was performed. One centimeter of the left colon was resected, and an end-to-end anastomosis was performed with single layer running sutures, with 6-0 polypropylene (Figure 1 ). The abdominal wall closure was performed with running sutures, in two layers, using 3-0 polypropylene. Postoperative analgesia was done with tramadol in a dose of $0,72 \mathrm{mg} / \mathrm{kg}$ at every 12 hours.

Peritonitis was induced, in all groups, by the method of Wichterman et al. [11] consisting of a partial ligation of the cecum with cotton suture, immediately below the triangular ileocecal fold to increase the pressure within that segment of the intestine without causing ischemia and allowing free passage of the contents of the small intestine into the large intestine. Then the cecum was perforated in 10 random points with a $40 \times 12 \mathrm{~mm}$ needle, followed by its compression for fecal leakage (Figure 2).

At 1,3 , or 7 post operative days (POD) the animals were weighed, anesthetized, re-operated and killed with an overdose of thionembutal intravenously.

The anastomotic breaking strength (ABS) was evaluated with a vertical test apparatus called Versa Test (Mecmesin Versa Test, United Kingdom), coupled to a portable digital dynamometer in which the colonic anastomosis samples were attached and pulled with a speed of $25 \mathrm{~mm} / \mathrm{min}$ [12].

The maximum traction force value that the tissue endured before rupture was measured in Newtons.

A sample of the anastomotic scar was collected for histopathological analysis, fixed in formalin and stained by hematoxylin and eosin. The amount of collagen,

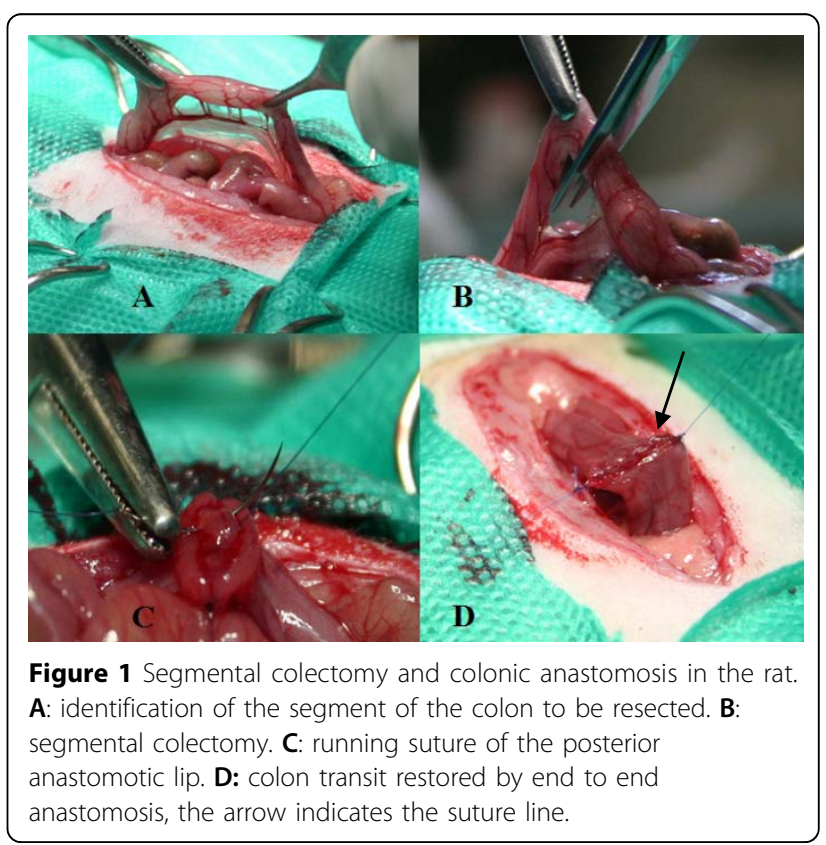




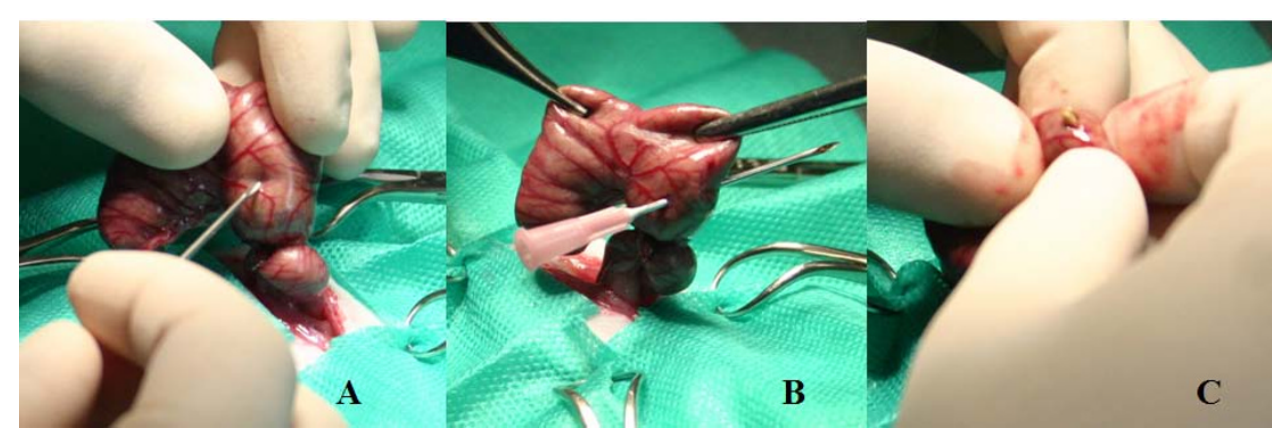

Figure 2 Wichterman sepsis induction method. A and B the cecum is perforated. C the cecum is squeezed to leak feces and induce the sepsis.

fibroblast, mononuclear and polymorphonuclear infiltrations and neovascularization were marked with values 0 , 1, 2 or 3 each, in which 0 means nothing and 3 a large amount. The parameters of abscess, bacterial colony, foreign body, crust and fibrin were signalized as 0 or 1 , meaning absent or present, respectively.

The results were analyzed using SPSS software (Special Package for Social Sciences) version 18.0. Parametric and nonparametric tests were performed, according to the nature of the variables. The paired samples $t$ test was used for the weight variations and Kruskal-Wallis test for anastomotic breaking strength. The Fisher exact test was used to perform the statistical analysis of all histopathological variables. Significance was set at a value of $\mathrm{p}<0.05$.

\section{Results}

There was an overall mortality of four deaths $(11,11 \%)$. Three animals from the group AS died (16,6\%), one of them in the subgroup AS1 and two in the AS7. In the S group only an animal died, in the $\mathrm{S} 3$ group, a death rate of $5,5 \%$. (Figure 3 ).

There was weight loss in almost every group, from the operation day to the day of euthanize $(\mathrm{p}<0,05)$, as shown in the Table 1 . The average preoperative weight of all groups was 321,05 grams, and the post operative weight was 299,6 grams.

The anastomotic breaking strength (ABS) was not different between groups AS and S, from the first to the third day ( $p>0.05)$. There was no statistical difference between groups AS1 and S1, AS3 and S3 or AS7 and S7 ( $\mathrm{p}>0.05$ ), Figure 4 and Table 2.

There was no difference between the groups AS1, AS3 and AS7 $(p>0,05)$. The S7 group had a higher anastomotic breaking strength than S1 and S3 $(\mathrm{p}<0,05)$. The AS group anastomotic breaking strength (ABS) had a sharper decline than the $S$ group from the first to the third day, and at the seventh day the AS group ABS was not recovered (Figure 5).

On the histopathological evaluation there was no difference of any of the analyzed parameters between groups AS and S (Table 3). There was no difference of collagen between the groups AS7 and S7 ( $>>0.05)$.

\section{Discussion}

The aim of this study was to evaluate the effects of acute ethanol exposure at single high dose just before an injury in rats with fecal sepsis. To evaluate that, we have analyzed the death rate, weight variations, anastomosis breaking strength and histopathology.

Both alcohol and sepsis are known to lead to weight loss after surgery, and their combination diminished the post-operative body mass in this study, and even at the 7 POD that weight wasn't recovered [13,14]. Sepsis leads to a consumptive syndrome due to the inflammation and alcohol intake is responsible for malnutrition because of intestinal malabsorption and is also responsible for body fat reduction $[13,14]$.

Sepsis is an important cause of death in trauma patients. It was the cause of $9 \%$ of deaths in a level I trauma centre in USA in 2003 [15]. Alcohol is also a

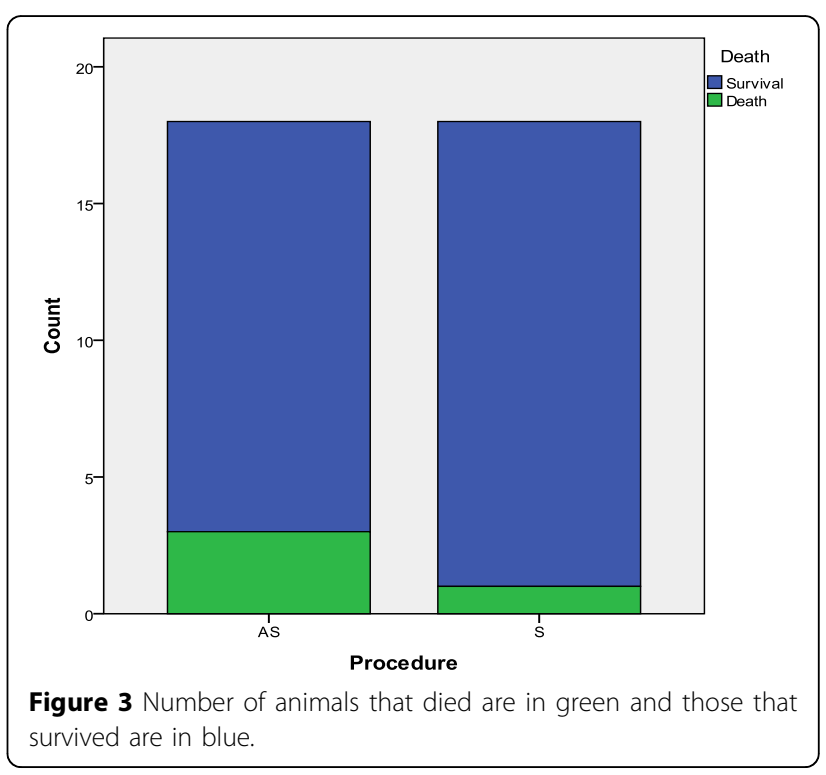


Table 1 Preoperative and postoperative average weight of each group. The statistically significant differences were signaled.

\begin{tabular}{cccc}
\hline \multicolumn{4}{c}{ Weight per group } \\
\hline & Preoperative & Postoperative & P \\
\hline AS1 & 320,2 & 309,7 & $<0,05^{*}$ \\
AS3 & 326,0 & 291,3 & $<0,05^{*}$ \\
AS7 & 292,6 & 269,4 & $<0,05^{*}$ \\
S1 & 351,6 & 348,3 & $>0,05$ \\
S3 & 308,9 & 272,1 & $<0,05^{*}$ \\
S7 & 313,8 & 292,6 & $<0,05^{*}$ \\
\hline
\end{tabular}

risk factor for death in animal models and human patients $[13,16,17]$. This study showed that the combination of alcohol and sepsis have an even greater impact on postoperative mortality, since the group AS had a death rate three times greater the $\mathrm{S}$ group.

The scar tissue healing can be mechanically evaluated by both longitudinal anastomotic breaking strength (ABS) used in our study and radial bursting strength $[13,18]$. Longitudinal breaking strength is the measure of intestinal wall resistance to forces applied on its longitudinal direction while bursting pressure measures the resistance to intraluminal elevated preassures [19]. The ABS measures the risk for total dehiscence, because it measures the strength of the scar's strongest bit, while the bursting pressure evaluates the risk of leakage, because it measures the strength of the weakest segment of the scar.

The AS group colon surgical wound didn't became stronger by day 7 , because it was not different from the 3 AS or the 1 AS groups $(p>0,05)$. The acquisition of

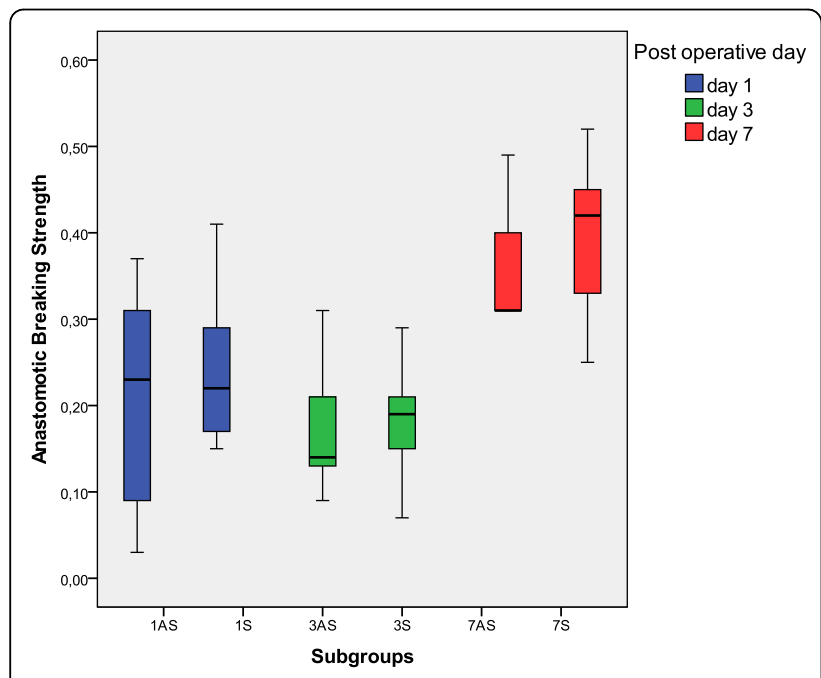

Figure 4 Anastomotic breaking strength distribution in Newtons: superior and inferior limits, interquartils interval and the median in the central part of the boxes. All groups have been displayed.
Table 2 Minimum, Maximum, median, mean and standard deviation for the colonic anastomosis breaking strength at each group and subgroups. Values measured in Newtons.

\begin{tabular}{ccccccc}
\hline \multicolumn{7}{c}{ Anastomosis Breaking Strength } \\
\hline AS1 & S1 & AS3 & S3 & AS7 & S7 \\
\hline n (survived) & 5 & 6 & 6 & 5 & 4 & 6 \\
Minimum & 0,03 & 0,15 & 0,09 & 0,07 & 0,31 & 0,25 \\
Maximum & 0,37 & 0,41 & 0,31 & 0,29 & 0,49 & 0,52 \\
Median & 0,23 & 0,22 & 0,14 & 0,19 & 0,31 & 0,42 \\
Mean & 0,20 & 0,24 & 0,17 & 0,18 & 0,35 & 0,40 \\
Std. Deviation & 0,14 & 0,09 & 0,08 & 0,08 & 0,09 & 0,09 \\
\hline
\end{tabular}

tensile strength of the wound is due to the deposition and organization of the collagen, and an impaired wound healing is responsible not only for the lack of collagen, but also for disorganized collagen [1]. It is possible that the alcohol intake was responsible for an impaired inflammation stage of the wound healing and magnified the deleterious effects of sepsis, such as disorganized deposition of collagen and excessive activity of matrix metalloproteases [1,20-22].

The effects of alcohol on wound healing are dependent to the pattern of the alcohol exposure: chronic or acute abuse, the dose intake, duration of consumption, time from alcohol exposure to injury, alcohol withdrawal and associated factors such as infection, sepsis, smoking, usage of medication, obesity, diabetes, and other comorbidities [1]. Acute ethanol exposure in non-septic patients can

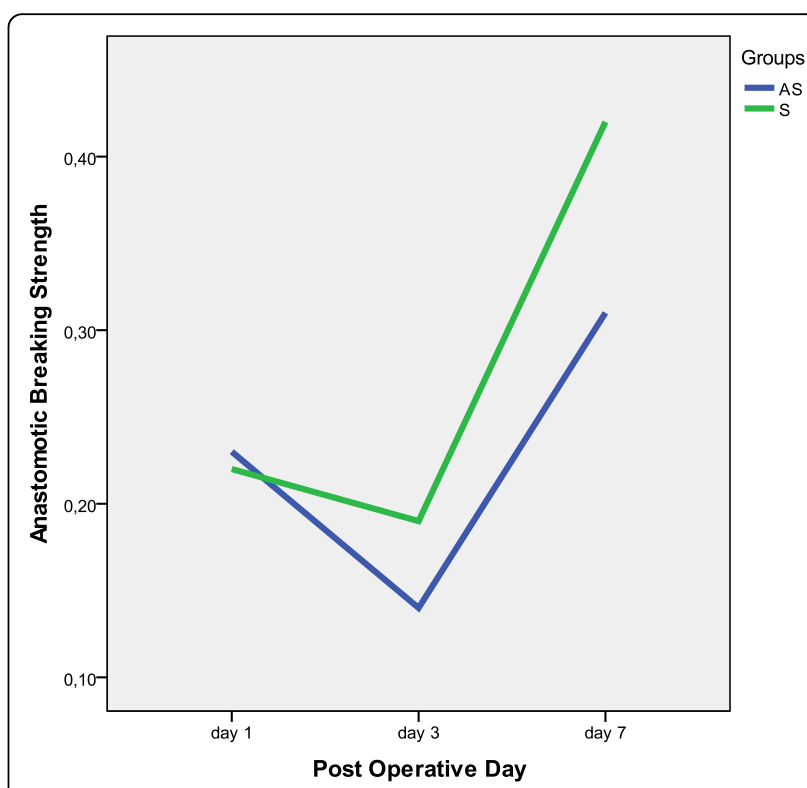

Figure 5 Median of the anastomotic breaking strength, in Newton, one, three and seven post-operative days. Even after 7 days the AS group (blue) colonic anastomosis did not become stronger $(p>0,05)$ while the $S$ group (green) did $(p<0,05)$. 
Table 3 Sum of the values of all animals of the groups due to the analyzed histopathological parameters. The amount of collagen, fibroblast, mononuclear and polymorphonuclear infiltrations and the neovascularization were marked with values from 0 to 3 each, in which 0 means nothing and 3 a large amount. The parameters of abscess, bacterial colony, foreign body, crust and fibrin were signalized as 0 or 1 , meaning absent or present respectively.

\begin{tabular}{ccccccc}
\hline \multicolumn{7}{c}{ Histopathological Analysis } \\
\hline & AS1 & S1 & AS3 & S3 & AS7 & S7 \\
& $\mathrm{n}=5$ & $\mathrm{n}=6$ & $\mathrm{n}=6$ & $\mathrm{n}=5$ & $\mathrm{n}=4$ & $\mathrm{n}=6$ \\
\hline Collagen & 0 & 0 & 0 & 0 & 4 & 6 \\
Fibroblast & 0 & 0 & 6 & 5 & 12 & 18 \\
Neovascularization & 0 & 0 & 6 & 5 & 8 & 12 \\
Mononuclear & 0 & 0 & 6 & 5 & 8 & 12 \\
Polymorphonuclear & 7 & 6 & 15 & 13 & 9 & 13 \\
Abscess & 1 & 0 & 4 & 4 & 1 & 1 \\
Bacterial Colony & 1 & 1 & 2 & 5 & 2 & 1 \\
Foreign Body & 1 & 0 & 2 & 3 & 4 & 5 \\
Crust & 5 & 6 & 4 & 5 & 3 & 4 \\
Fibrin & 4 & 5 & 6 & 5 & 0 & 0 \\
\hline
\end{tabular}

lead to inadequate wound healing, by impairing the early inflammatory response, inhibiting wound closure, angiogenesis and collagen production, and changing the protease balance at the wound site [1], although we didn't observe this in the septic conditions of this study.

Inflammation is a normal part of the wound healing process, and is important to the removal of contaminating micro-organisms [1]. In the absence of effective decontamination, such as in fecal sepsis, inflammation may be prolonged, thus the next steps in wound healing, the inflammation and remodeling, can be prolonged or impaired, but not always [1]. Both bacteria and endotoxins can lead to prolonged elevation of pro-inflammatory cytokines such as interleukin-1 (IL-1), IL-6, IL-10, TNF$\alpha$, and increased levels of matrix metalloproteases (MMP) [1,20-22].

\section{Conclusions}

Sepsis and its association with ethanol led to weight loss postoperatively. Alcohol intake increased the mortality rate three times in septic animals. Acute alcohol intoxication delays the acquisition of tensile strength of colonic anastomosis in septic rats. Therefore, acute alcohol intoxication before sepsis leads to worse prognosis in animal models of abdominal trauma patients.

\section{Acknowledgements}

This research was only possible through the support from the following institutions: $2^{\text {nd }} / 2010$ grants of FINATEC (Foundation of Scientific and Technological Developments), supply of Wistar rats by the Labocien of UniCEUB (University Center of Brasilia), scientific initiation scholarships from the University of Brasília (UnB) and CNPq (National Council of Research and Development).

Also thanks to Gabizao Alves for the high quality professional photos, displayed as Figures 1 and 2 .

Finally we must thank the Academic League of Emergency and Trauma of the University of Brasilia (LETUnB) for supporting us and supplying our minds with ideas and curiosity for trauma, emergency and surgery.

This article has been published as part of World Journal of Emergency Surgery Volume 7 Supplement 1, 2012: Proceedings of the World Trauma Congress 2012. The full contents of the supplement are available online at http:// www.wjes.org/supplements/7/S1

\section{Author details}

${ }^{1}$ Medical School, Academic League of Emergency and Trauma, University of Brasilia, Brasilia, Brazil. ²Medical School, University of Brasilia, Brasilia, Brazil. ${ }^{3}$ Campus Universitário Darcy Ribeiro, Prédio da Reitoria, $2^{\circ}$ pavimento, sala B2-16, 70910-900 Brasília - DF Brasil, Brazil.

\section{Authors' contributions}

PHAM did the project design and coordination, surgical and technical work, statistical analysis, data acquisition and interpretation and manuscript writing. VLR, IECF and LEAS all did the project design, surgical and technical work, data acquisition and interpretation. FPC was responsible for the histopathological work and data interpretation. JPRV helped with the project design, technical work and data interpretation. JBS did the data interpretation, critical review and manuscript writing. All authors read and approved the final manuscript.

\section{Competing interests}

The authors declare that they have no competing interests of any kind.

\section{Published: 22 August 2012}

\section{References}

1. Guo S, Dipietro LA: Factors affecting wound healing. J Dent Res 2010, 89:219-29

2. Miller PR, Fabian TC, Croce MA, Magnotti LJ, Pritchard FE, Minard G, Stewart RM: Improving outcomes following penetrating colon wounds: application of a clinical pathway. Ann Surg 2002, 235:775-81.

3. Ott MM, Norris PR, Diaz JJ, Collier BR, Jenkins JM, Gunter OL, Morris JA: Colon anastomosis after damage control laparotomy: recommendations from 174 trauma colectomies. The Journal of Trauma 2011, 70:595-602.

4. Osborn TM, Tracy JK, Dunne JR, Pasquale M, Napolitano LM: Epidemiology of sepsis in patients with traumatic injury. Crit Care Med 2004, 32:2234-40.

5. Rangel-Frausto MS: Sepsis: still going strong. Arch Med Res 2005, 36:672-81.

6. Lieber CS: Medical disorders of alcoholism. N Engl J Med 1995, 333:1058-65

7. Smith GS, Brenas CC, Miller TR: Fatal Nontraffic Injuries Involving Alcohol: A Metanalysis. Annals of emergency medicine 1999, 33:659-668.

8. Gazal-Carvalho C, Carlini-Cotrima B, Silvab OA, Sauaia N: Blood alcohol content prevalence among trauma patients seen at a level 1 trauma Center. Rev Saúde Pública 2002, 36:47-54.

9. Gentilello LM, Rivara FP, Donovan DM, Jurkovich GJ, Daranciang E, Dunn CW, Villaveces A, Copass M, Ries RR: Alcohol Interventions in a Trauma Center as a Means of Reducing the Risk of Injury Recurrence. Ann of Surg 1999, 230:473-483.

10. Spies CD, Rommelspacher H: Alcohol Withdrawal in the Surgical Patient: Prevention and Treatment. Anesth Analg 1999, 88:946-54.

11. Wichterman KA, Baue AAAE, Chaudry $\mathrm{IH}$ : Sepsis and septic shock - a review of laboratory models and a proposal. J Surg Res 1980, 29:189-201.

12. Morais PH, Farias IC, Duraes LC, Carneiro FP, Oliveira PG, Sousa JB: Evaluation of the effects of carbon dioxide pneumoperitoneum on abdominal wall wound healing in rats undergoing segmental resection and anastomosis of the left colon. Acta Cir Bras 2012, 27:63-70.

13. Pereira RSC, Hasimoto CN, Pelafsky L, Llanos JC, Cataneo DC, Spadella CT, Minossi JG: Intestinal healing in rats submitted to ethanol ingestion. Acta Cir Bras 2012, 27:236-43.

14. Silva SM, Oliveira MVM, Brandao AM, Carneiro FP, Ferreira VMM, Parra RS, Feres O, Sousa JB: Study on adhesion formation and the healing of colon anastomosis in rats with induced peritoneal sepsis. Acta Cir Bras 2011, 26:100-5. 
15. Stwart RM, Myers JG, Dent DL, Ermis P, Gray GA, Villarreal R, Blow O, Woods B, McFarland M, Garavaglia J, Root HD, Pruitt BA Jr: Seven hundred fifty-three consecutive deaths in a level I trauma center: the argument for injury prevention. J Trauma 2003, 54:66-71.

16. Tonnesen $\mathrm{H}$, Kehlet $\mathrm{H}$ : Preoperative alcoholism and postoperative morbidity. Br J Surg 1999, 86:869-74.

17. Radek KA, Matthies AM, Burns AL, Heinrich SA, Kovacs EJ, DiPietro LA: Acute alcohol exposure impairs angiogenesis and the proliferative phase of wound healing. Am J Physiol Heart Circ Physiol 2005, 289:H1084-90.

18. Thompson SK, Chang EY, Jobe BA: Clinical Review: healing in gastrointestinal anastomosis. Microsurgery 2006, 26:131-6.

19. Mansson P, Zhang XW, Jeppsson B, Thorlaciuss H: Anastomotic healing in the rat colon: comparison between a radiological method, breaking strength and bursting pressure. Int J Colorectal Dis 2002, 17:420-5.

20. Ishimura K, Tsubouchi T, Okano K, Maeba T, Maeta H: Wound Healing after digestive surgery under septic conditions: participation of local interleukin-6 expression. World J Surg 1998, 22:1069-76.

21. Ishimura K, Moroguchi A, Okano K, Maeba T, Maeta H: Local expression of tumor necrosis factor and interleukin-10 on wound healing of intestinal anastomosis during endotoxemia in mice. J Surg Res 2002, 108:91-97.

22. Teke Z, Sacar S, Yenisey C, Atalay AO: Role of activated protein C on Wound Healing process in left colonic anastomoses in presence of intraabdominal sepsis induced by cecal ligation and puncture: an experimental study in rat. World J Surg 2008, 32:2434-43.

doi:10.1186/1749-7922-7-S1-S10

Cite this article as: Morais et al:: Alcohol acute intoxication before sepsis impairs the wound healing of intestinal anastomosis: rat model of the abdominal trauma patient. World Journal of Emergency Surgery 20127 (Suppl 1):S10.

\section{Submit your next manuscript to BioMed Central and take full advantage of:}

- Convenient online submission

- Thorough peer review

- No space constraints or color figure charges

- Immediate publication on acceptance

- Inclusion in PubMed, CAS, Scopus and Google Scholar

- Research which is freely available for redistribution

Submit your manuscript at www.biomedcentral.com/submit 